\title{
Hydrogeochemical Assessment of Metals Contamination in an Urban Drainage System: A Case Study of Osogbo Township, SW-Nigeria
}

\author{
Moshood N. TIJANI ${ }^{1}$, Shinichi ONODERA ${ }^{2}$ \\ ${ }^{1}$ Dept. of Geology, University of Ibadan, Ibadan, Nigeria \\ ${ }^{2}$ Biogeochemistry Laboratory, Hiroshima University, Higashi-Hiroshima, Japan \\ E-mail:tmoshood@yahoo.com \\ Received May 29, 2009; revised July 4, 2009; accepted July 9, 2009
}

\begin{abstract}
With increasing urban population, attention had been focused on environmental degradation of urban drainage system with respect to trace/heavy metal contaminations. Such concerns underlie the ever-increasing impacts of urbanization and industrial activities on urban watershed in the developing regions of the world, especially in areas with inadequate land-use plan and poor waste disposal and management practices. Hence, this study highlights the hydrogeochemical assessment of surface water and bottom-sediment samples from an urban drainage system in Osogbo Township, SW-Nigeria with respect to trace metals contaminations.

The results show that the surface water samples have generally low TDS with average value of $362 \mathrm{mg} / \mathrm{l}$, while the average dissolved concentrations of the trace metals $(\mathrm{Cu}, \mathrm{Pb}, \mathrm{Zn}, \mathrm{Ni}$, As and $\mathrm{Cr}$ ) vary from 0.01 to $0.5 \mathrm{mg} / \mathrm{l}$. Cu, $\mathrm{Cr}$ and As exhibit concentrations similar to the local background concentrations (LBC) in the pristine stream water with low single metal contamination factor $(\mathrm{CF} \approx 1)$. $\mathrm{Pb}, \mathrm{Zn}$ and $\mathrm{Ni}$ are 5 folds enriched with contamination factor $(\mathrm{CF})$ of $>5$ indicating moderate to high contamination. For the sediment phase, the adsorbed concentrations of the trace metals $(\mathrm{Cu}, \mathrm{Pb}, \mathrm{Zn}, \mathrm{Ni}, \mathrm{As}, \mathrm{Cr}$ and $\mathrm{Co}$ ) vary between 0.1 to $3.1 \mathrm{mg} / \mathrm{kg}$. These represent about 1 to $3 \%$ of the respective total metal concentrations with average values of $18.2-$ $533.4 \mathrm{mg} / \mathrm{kg}$. Also low anthropogenic factor, AF ( 0.002 to 0.08$)$ and mostly negative values ( -5 to -15$)$ of Mueller's geo-accumulation index ( $\mathrm{I}_{\mathrm{geo}}$ ) for adsorbed metal contents in the sediments suggest dominant geogenic controls.

However, the total metals concentrations in the sediment phase have high estimated AF of 1.1 to 9.3 and positive values of the estimated Igeo (0.9-2.0) and metal contamination index (MCI) of 2.5-8.3. All these suggest a medium to high level enrichment (of 2 to 10 factor) for most of the metals with respect to the local background concentration (LBC) in the basement bedrock units (with the exception of $\mathrm{Cr}$ and Ni). This is consistent with the preferential metal enrichment in the sediment phase as indicated by the estimated partitioning/distribution coefficient, $K_{d}$ of $>1$ exhibited by the total metal concentrations in the stream sediment. Nonetheless, the correlated high peaks of electrical conductivity of the stream water samples and adsorbed concentrations of some trace metals within the urban stretches are indications of point source inputs of untreated sewage into the drainage system.
\end{abstract}

Keywords: Urban Drainage System, Heavy Metals Contamination, Bioavailability, Water Quality, Stream Sediments

\section{Introduction}

Hydrogeochemical surveys of drainage systems have long been employed not only as geochemical exploration tool but to provide information on contaminant metals sources in relation to weathering and erosion transport processes within the catchment area [1-3]. However, a number of studies had shown that trace metals in-puts 
into the aquatic systems can be through; a) geogenic sources, related to the processes of weathering, erosion and sedimentation of geological units within the catchment area and b) anthropogenic sources, related to human activities that cause enrichment of metals in river waters and bottom sediments [4-8]. In essence, the quality of water in surface drainage system is a function of anthropogenic influences (urbanization, agricultural and industrial activities) as well as natural processes (weathering and catchment erosion) [9].

However, there had been increasing concerns about degradation of urban drainage systems with respect to trace/heavy metal contaminations, in the recent past [5]. This environmental concern is apparently due to the toxicity and perceived persistency of trace metals within the drainage/aquatic systems. Such concerns underlie the ever-increasing impacts of urbanization, agricultural, mining and industrial activities on surface drainage systems. This is more so in the developing regions of the world, especially in areas with inadequate land use plan and lack of proper waste disposal and management practices $[10,11]$.

By and large, there had been a number of global or international efforts such as UNESCO-assisted IGCP $259 / 360$ on standardization of geochemical mapping methodology and Geochemical Reference Network of the IUGS Working Group on Global Geochemical Baseline. These efforts, most of which are in the developed regions of the world, are in parts to address the need for reliable baseline data in respect of trace/heavy metals inputs into the environment. However, there are little and uncoordinated efforts in the developing countries in respect of baseline studies of trace/heavy metals contaminations, even though contamination level may be as high as that of developed/industrialized countries [10,12].

Sediments are said to represent the ultimate sinks for trace/heavy metals in the environment [13-15], because of large specific surfaces for the metal sorption [8]. However, changing environmental conditions may lead to remobilization and release of metal pollutants into the water column and consequently enters into the tropic levels of the food chain within an aquatic/drainage environment. The implication of this is increasing bioavailability and toxicity, which may result to serious health and environmental consequences.

This study presents the contamination assessment of an urbanized drainage catchment in SW-Nigeria, and highlights possible impacts of urbanization and associated anthropogenic activities on the distribution of trace metals in both water and sediment phases of the drainage networks in the study area. In this study we a) describe the distribution of the selected trace metals in both water and sediment phases, b) assess the extent of metal con- tamination and possible influence/contribution of the underlying bedrock geology and anthropogenic activities within the catchment area and c) provide basis for environmental contamination control/monitoring.

\section{Study Area}

\subsection{Location and Environmental Settings}

The Osogbo area where the present study is confined is located within latitude $7^{\circ} 6^{\prime} \mathrm{N} \& 7^{\circ} 15^{\prime} \mathrm{N}$ and longitude $3^{\circ} 17^{\prime} \mathrm{E} \& 3^{\circ} 25^{\prime} \mathrm{E}$ and covers about $268 \mathrm{~km}^{2}$. It is located in SW part of Nigeria (Figure 1). Osogbo-Township is a well-known ancient /cultural urban centers before been named as the capital city of the Osun state in 1991. Subsequently Osogbo township become the focus of both political and socio-economic activities and, therefore, a major recipient of migrants from various parts the state. With a population of about 105,000 in 1991, Osogbo had since witnessed tremendous population growth with an estimated current population of about 220,000 based on the projected $3 \%$ annual growth.

Like many emerging cities in developing countries, such rapid urbanization are not usually matched with corresponding adequate urban planning and increase in provision of utility services such as water supply, sewage lines and adequate waste management practices. Therefore, the rapid transformation of Osogbo as ancient/cultural centers into a modern urban enclave had resulted in negative impacts on the quality of the urban drainage system within township area. Plate $\mathbf{1}$ and $\mathbf{2}$ highlight typical environmental scenario where urban drainage systems serve as recipient of household and municipal effluents as well as refuse dumps. Hence, this underpins the need to appraise the quality status and environmental contamination of the urban drainage system in the study area.

\subsection{Geological and Climatic Setting}

Geologically, the study area lies largely within the Precambrian Basement Complex of Southwestern Nigeria, and belongs to the Pan African mobile belt east of West African Craton. The major rock groups in the study area are migmatite complex (including banded and auguen gneisses as well as pegmatites) and metasediments (consisting of schists quartzites and amphibiolites in places). The dominant basement rocks in Osogbo area (Figure 2) are schist and migmatites, associated with quartzite ridges forming the characteristic undulating terrain. Further details about the geology of the Basement Complex are described elsewhere in past studies [16-18].

Surficial materials are characterized by relatively deeply weathered soil profile or regolith in the low lying 
areas, due to the relatively humid climatic conditions. Greater proportions of the soils are ferruginous tropical red soils (laterites) associated with Basement Complex terrains. Regionally, soil degradation and soil erosion are generally minimal due to compactness of the surficial material, however, debris wash along the slopes of the hills are common. The area, falls within the lowland tropical rain forest vegetation most of which had since given way to secondary forest and derived savannah. Such secondary vegetations are due to fuel wood production, quarrying and traditional farming practices as well as other developmental projects like road constructions.

The climate is tropical hinterland type with mean annual temperature of about $27^{\circ} \mathrm{C}$. Two main climatic sea- sons are: a dry season which starts from November to early March and a wet season between late March and early November with mean annual rainfall of 1000 $1250 \mathrm{~mm}$. The drainage pattern is moderately dense and dendritic, dominated by Osun River and its tributaries (Figure 2), which are largely controlled by the structural trends within the Basement Complex terrain.

\section{Methodology}

\subsection{Sampling and Laboratory Analyses}

In this study a total number of thirty-eight (38) bottom sediment samples and the corresponding stream water

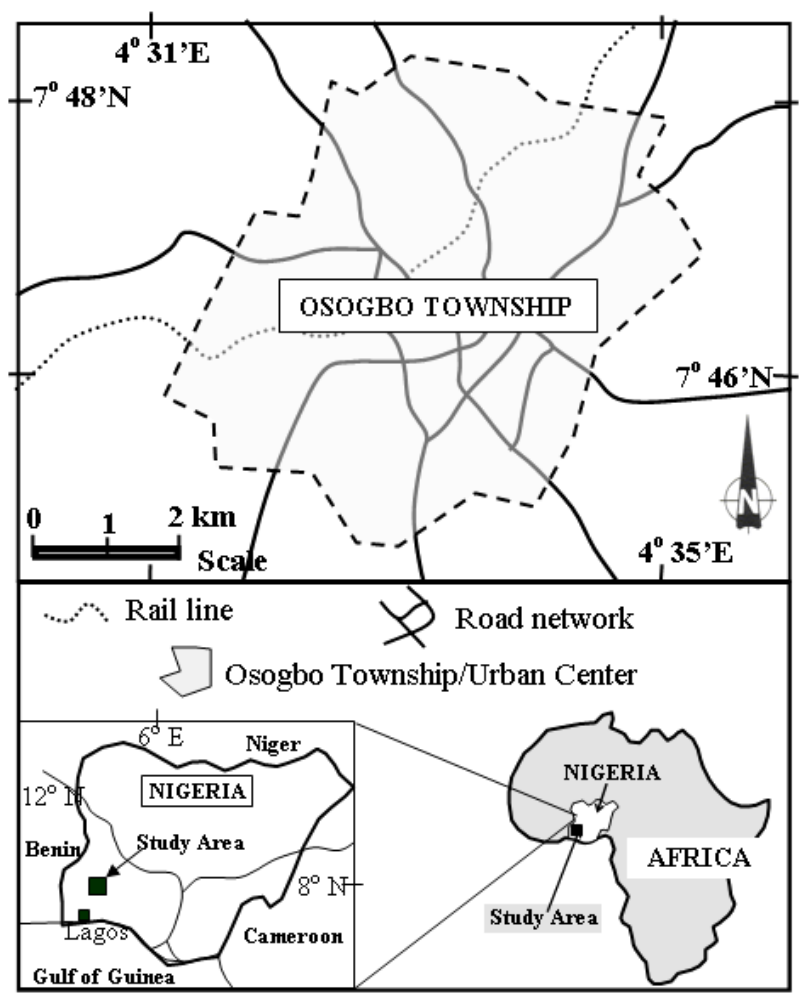

Figure 1. Location Map of the study area with in-set reference map.

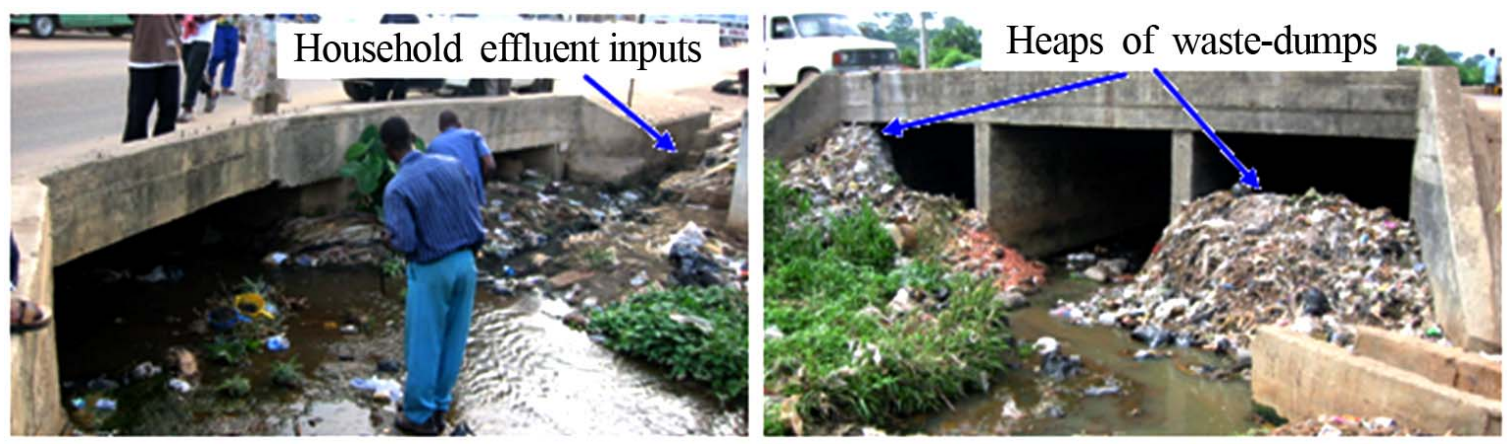

Plate 1 and 2. Polluted urban stream channels with sewage water and solid waste dumps. 


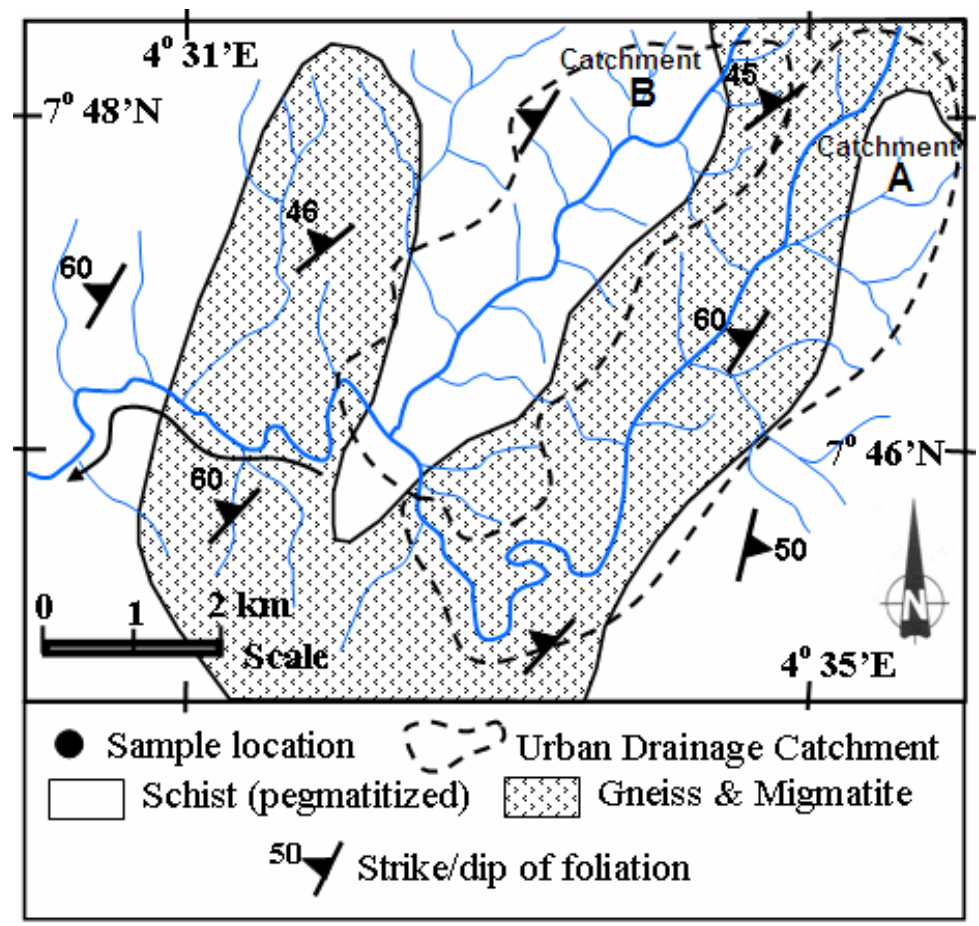

Figure 2. Geological Map of the study area with superimposed drainage system.

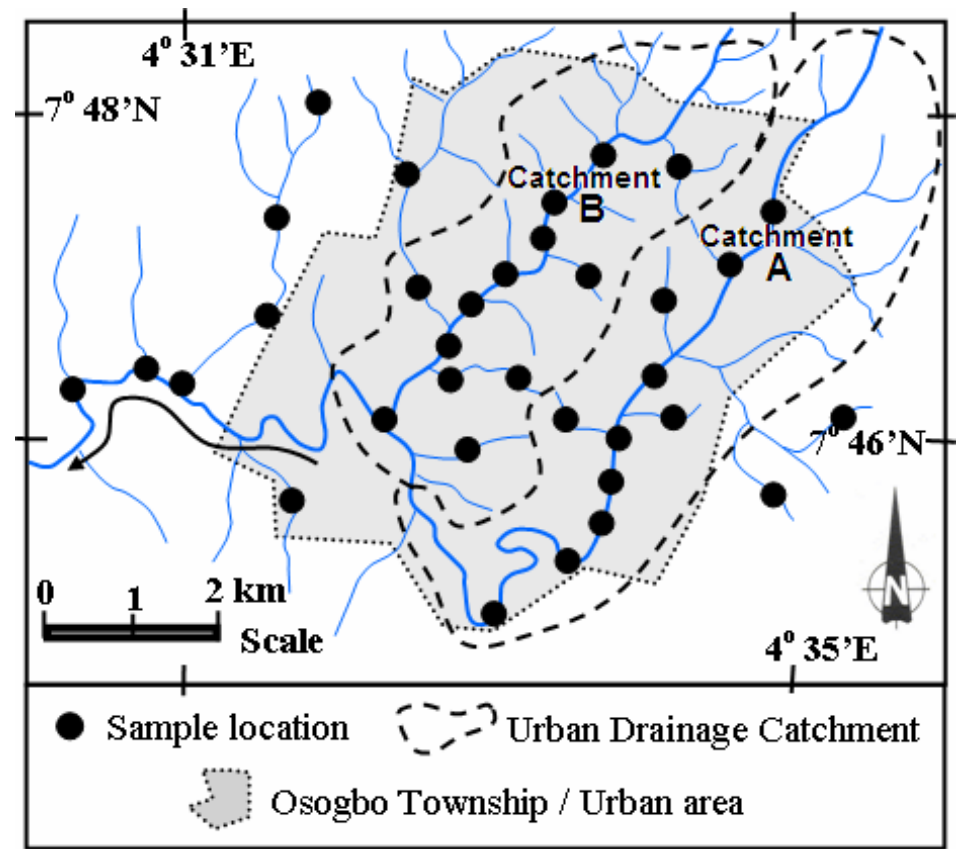

Figure 3. Map of the drainage system of the study area with sample locations.

samples were collected for geochemical analyses. Areal coverage of the sample locations was controlled mostly by accessibility while efforts were made to ensure even distribution within the urban drainage network in the study area (Figure 3). Water samples were collected in plastic bottles following standard sampling procedure
[19]. Sensitive physical parameters such as temperature, $\mathrm{pH}$, electrical conductivity (EC) and total dissolved solid (TDS) were determined in-situ using WTW $\mathrm{pH} / 91 \mathrm{pH}$ meter and WTW LF/95 conductivity meter.

Water samples collected were acidified and preserved (refrigerated) prior to analyses of dissolved metal con- 
centrations. Stream sediment samples were collected in clean polythene bags using plastic shovel and sieves to avoid contamination and to drain off the water. The sediment samples were later air-dried in the laboratory, disaggregated and sieved to obtain the clay fractions $(<63 \mu \mathrm{m})$. The use of fine portions (clay fractions) was as a result of their role as metal accumulators, due to their net negative charge and participation in sorption and cation exchange processes. Subsequent to initial sample preparation, the adsorbed content of selected trace/heavy metals ( $\mathrm{Mn}, \mathrm{Cu}, \mathrm{Pb}, \mathrm{Zn}, \mathrm{Ni}, \mathrm{As}, \mathrm{Cr}, \mathrm{Co}$ ) in the clay fractions were extracted using $1.0 \mathrm{M}$ solution of ammonium acetate. The trace metals concentrations of the extract solutions alongside with the acidified/preserved stream water samples (for all the 38 locations) were then analyzed using ICP-AES method (Perkin Elmer; model OPTIMA 3000 ) at the Biogeochemistry Laboratory, Hiroshima University, Japan. However, about 15 of the stream sediment samples were selected for additional analyses of the total metal concentrations using X-ray florescence (XRF) method (Rigaku ZSX, Japan) at the Department of Earth Sciences, Hiroshima University, Japan.

\subsection{Data Evaluation}

As part of data evaluation, statistical summary and correlation analysis were used to ascertain the interdependence of the parameters. Furthermore, quantification of contamination indices such as anthropogenic factor (AF), enrichment factor (EF), metal contamination Index (MCI) and geo-accumulation index (Igeo) for the bottom sediments and contamination factor (CF) for the waters samples were also undertaken. Brief highlights of these indices are presented below, while further details can be found elsewhere in related studies [20-23].

a) Anthropogenic contamination factor (CF) and degree of contamination $\left(\mathrm{C}_{\mathrm{deg}}\right)$ : these are quantification of the degree of contamination as single-metal index (CF) and as overall degree of contamination $\left(\mathrm{C}_{\mathrm{deg}}\right)$. The measure is relative to either average crustal composition of the respective metal or to a measured background values from a geologically pristine/ uncontaminated area;

$$
\begin{aligned}
\mathrm{CF} & =\mathrm{C}_{\mathrm{m}} / \mathrm{B}_{\mathrm{m}} \\
\mathrm{C}_{\mathrm{deg}} & =\sum\left\{\mathrm{C}_{\mathrm{m}} / \mathrm{B}_{\mathrm{m}}\right\}_{\mathrm{i}}
\end{aligned}
$$

where i represents the respective metals (i.e. $\mathrm{Cu}, \mathrm{Pb}, \mathrm{Zn}$, $\mathrm{Cd}, \mathrm{Fe}, \mathrm{Mn}) ; \mathrm{C}_{\mathrm{m}}$ is the measured concentration in sediment or water while $B_{m}$ is the local background concentration (value) of metal (m) within the pristine area of the catchment. For the $\mathrm{C}_{\mathrm{deg}}$, Hakanson recognized four descriptive classes [24], with values of $<8$ to $>32$ whereby $\mathrm{C}_{\mathrm{deg}}<8$ implies low degree of contamination and $\mathrm{C}_{\mathrm{deg}}>32$ implies very high degree of contamination. b) Elemental contamination index (ECI) and overall metal contamination index (MCI) are expression of single metal contamination within a sample or combined metal contamination for a sample relative to the background values of the respective metal and are expressed as:

$$
\begin{gathered}
\mathrm{ECI}=\left(\mathrm{C}_{\mathrm{m}}-\mathrm{B}_{\mathrm{m}}\right) / \mathrm{B}_{\mathrm{m}} \\
\mathrm{MCI}=\sum\left\{\left(\mathrm{C}_{\mathrm{m}}-\mathrm{B}_{\mathrm{m}}\right) / \mathrm{B}_{\mathrm{m}}\right\}_{\mathrm{i}}
\end{gathered}
$$

where, $i, C_{m}$, and $B_{m}$ are as earlier defined above. According to Meybeck et al., [22], MCI was designed to describe general trace elements contamination on a scale from 0 to 100 , with MCI of $<5$ implies very low contamination; $5-10=$ low contamination; $10-25=$ medium contamination; 25-50 high contamination; $50-100=$ very high contamination and $>100$ implies extremely high contamination.

c) Normalized enrichment factor (n-EF): this was based on the standardization of the analyzed metals against a conservative reference element. Such reference elements (e.g. Sc, Mn, Ti Al and Fe) are usually characterized by low occurrence variability and uniform flux from crustal source-rocks [20,21]. In this study Al was used as a conservative reference metal since it has relatively higher precision of measurement as a major element and also it has been widely used as a normalizing metal in geochemical studies $[20,25,26]$.

$$
\mathrm{n} \text {-EF }=\left(\mathrm{C}_{\mathrm{m}} / \mathrm{C}_{\mathrm{Al}}\right) /\left(\mathrm{B}_{\mathrm{m}} / \mathrm{Al}_{\text {-backgrd }}\right)
$$

where, $C_{m}$ and $B_{m}$ are as defined above, while $C_{A l}$ is the measured concentration of $\mathrm{Al}$ in sediment or water. Albackgrd is the background concentration of reference element (Al) within the pristine area of the study catchment. Five descriptive categories of enrichment/contamination are defined based on the EF [20] with values of $<2$ to $>40$ whereby $\mathrm{EF}<2$ implies deficiency or minimal enrichment and EF $>40$ implies extremely high enrichment.

d) Index of Geoaccumulation (Igeo), as proposed by Mueller, [14] has also been widely used to evaluate the degree of metal contamination in terrestrial, aquatic as well as marine environments [20,27-29]. It is expressed as:

$$
\mathrm{I}_{\text {geo }}=\log _{2}\left[\left(\mathrm{C}_{\mathrm{m}}\right) /\left(1.5 * \mathrm{~B}_{\mathrm{m}}\right)\right]
$$

where $C_{m}$ and $B_{m}$ are as defined above, while 1.5 is a factor for possible variation in the background concentration due to lithologic differences. Igeo is classified into seven descriptive classes with values of $<0$ to $>5$ whereby $\mathrm{I}_{\mathrm{geo}}<0$ implies practically no contamination and open-ended $\mathrm{Igeo}_{\mathrm{ge}}>5$ implies very high/strong contamination. However, an Igeo of 6 is said to be indicative of 100 -fold enrichment of a metal with respect to the background value [14]. 


\section{Results and Discussions}

The summary of the results of geochemical analyses of the bottom sediment and water samples is presented in Table 1. As presented, the table shows the distribution of average concentrations of the adsorbed, total and dissolved concentrations of selected trace metals in sediment and water phases of the study urban drainage systems.

The average dissolved concentrations of the trace metals $(\mathrm{Cu}, \mathrm{Pb}, \mathrm{Zn}, \mathrm{Ni}, \mathrm{As}, \mathrm{Cr})$ vary from 0.01 to $0.5 \mathrm{mg} / \mathrm{l}$ compared to 0.1 to $3.1 \mathrm{mg} / \mathrm{kg}$ of the adsorbed portions in the sediment phase. However, the dissolved $\mathrm{As}, \mathrm{Cu}$ and $\mathrm{Cr}$ exhibit concentrations similar to the background concentrations in the pristine peri-urban stream waters. Higher concentrations of $\mathrm{Pb}, \mathrm{Zn}$, and $\mathrm{Ni}$ in the urban stream waters indicate anthropogenic inputs. On the other hand, the adsorbed trace metals in the sediment phase are considerably lower representing about 1 to $3 \%$ of the respective total metal concentrations in the sediments with average concentrations of $18.2-533.4 \mathrm{mg} / \mathrm{kg}$.

\subsection{Assessment of Trace Metal Contamination in the Water Phase}

Table 2 presents the summary of dissolved metals concentrations in the water. The average dissolved concentrations of the trace metals $(\mathrm{Cu}, \mathrm{Pb}, \mathrm{Zn}, \mathrm{Ni}, \mathrm{As}, \mathrm{Cr})$ vary from 0.01 to $0.5 \mathrm{mg} / 1$. However, $\mathrm{As}, \mathrm{Cu}$ and $\mathrm{Cr}$ exhibit concentrations similar to the background concentrations in the pristine peri-urban stream waters, compared to relatively higher concentrations of $\mathrm{Pb}, \mathrm{Zn}$, and $\mathrm{Ni}$ in the analyzed urban stream waters. Furthermore, like other trace metals, Figure 4 highlights the variability of $\mathrm{Cu}, \mathrm{Pb}$ and $\mathrm{Zn}$ in the water column of the urban stream network.

Table 1. Summary of the results of trace metal analyses in water and bottom sediment samples.

\begin{tabular}{cccccccccc}
\hline \multirow{2}{*}{$\begin{array}{c}\text { Trace } \\
\text { Metals }\end{array}$} & \multicolumn{2}{c}{$\begin{array}{c}\text { Sediment } \\
\text { (Adsorbed concentration) }\end{array}$} & \multicolumn{2}{c}{$\begin{array}{c}\text { Sediment } \\
\text { (Total concentration) }\end{array}$} & \multicolumn{2}{c}{ Water (mg/l) $\mathbf{N = 3 8}$ (Dissolved conc.) } \\
\cline { 2 - 10 } & Min & Max & Mean & Min & Max & Mean & Min & Max & Mean \\
\hline Mn & 1.49 & 153.2 & 20.27 & 775 & 2248 & 1204 & 0.21 & 12.4 & 2.08 \\
Cu & 0.08 & 1.60 & 0.34 & 38 & 211 & 115 & 0.04 & 0.09 & $\mathbf{0 . 0 5}$ \\
Pb & 0.06 & 1.50 & 0.23 & 50 & 751 & 237 & 0.00 & 0.14 & 0.05 \\
Zn & 0.58 & 10.89 & 3.01 & 74 & 964 & 533 & 0.08 & 3.98 & 0.50 \\
Ni & 0.00 & 0.38 & 0.03 & 15 & 40 & 30 & 0.001 & 0.03 & 0.01 \\
As & 0.07 & 0.14 & 0.10 & nd & nd & nd & 0.07 & 0.11 & $\mathbf{0 . 0 8}$ \\
Cd & bdl & bdl & bdl & nd & nd & nd & 0.001 & 0.09 & 0.03 \\
Cr & 0.07 & 0.14 & 0.09 & 65 & 125 & 87 & 0.09 & 0.12 & 0.10 \\
Co & 0.12 & 4.12 & 0.28 & 10 & 37 & 18 & bdl & bdl & bdl \\
Hg & 0.06 & 0.67 & $\mathbf{0 . 2 9}$ & nd & nd & nd & bdl & bdl & bdl \\
\hline
\end{tabular}

bdl = below detection limit; $n d=$ not determined.

Table 2. Summary of trace metal concentrations in the water phase and metal contamination indices.

\begin{tabular}{|c|c|c|c|c|c|c|}
\hline \multirow{2}{*}{ Metals } & \multicolumn{4}{|c|}{ Dissolved concentration $(\mathrm{mg} / \mathrm{l}) \mathrm{N}=32$} & \multirow[t]{2}{*}{$\mathrm{CF}^{*}$} & \multirow[t]{2}{*}{$\mathbf{K d}^{*}$} \\
\hline & Min & Max & Mean & Control & & \\
\hline Copper (Cu) & 0.04 & 0.09 & 0.05 & 0.04 & 1.4 & 6.7 \\
\hline Lead (Pb) & 0.00 & 0.14 & 0.05 & 0.003 & 15.9 & 16.0 \\
\hline Zinc (Zn) & 0.08 & 3.98 & 0.50 & 0.08 & 5.9 & 17.0 \\
\hline Nickel (Ni) & 0.001 & 0.03 & 0.01 & 0.001 & 12.2 & 1.8 \\
\hline Arsenic (As) & 0.07 & 0.11 & 0.08 & 0.07 & 1.1 & 1.3 \\
\hline Chromium (Cr) & 0.09 & 0.12 & 0.10 & 0.09 & 1.1 & 1.0 \\
\hline Cobalt (Co) & bdl & bdl & bdl & bdl & - & - \\
\hline
\end{tabular}

$* \mathrm{CF}=$ Single metal contamination factor; $\mathrm{Kd}=$ Metal partitioning coefficient;

$\mathrm{bdl}=$ below detection limit; Control $=$ Conc. of pristine peri-urban stream water sample. 


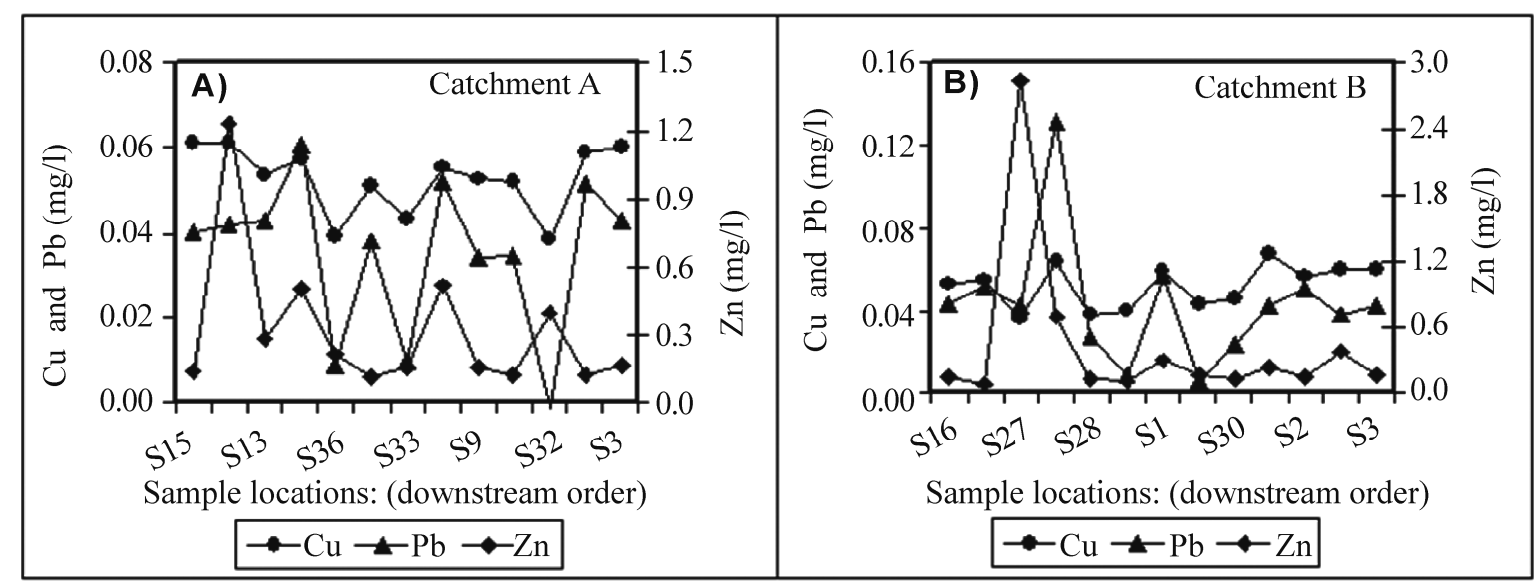

Figure 4. Profiles of trace metal concentrations in stream waters of the drainage catchment $A$ and $B$.

Table 3. Summary of trace metal concentrations in the sediments and contamination indices.

\begin{tabular}{|c|c|c|c|c|c|c|c|c|c|}
\hline \multirow[t]{2}{*}{ Metals } & \multicolumn{4}{|c|}{$\begin{array}{l}\text { Sediment (mg/kg) N=32 } \\
\text { (Adsorbed concentration) }\end{array}$} & \multicolumn{4}{|c|}{$\begin{array}{l}\text { Sediment (mg/kg) N=15 } \\
\text { (Total concentration) }\end{array}$} & \multirow[t]{2}{*}{ LBC* (mg/kg) } \\
\hline & Mean & $\mathrm{AF}$ & Igeo & MCI & Mean & $\mathrm{AF}$ & Igeo & MCI & \\
\hline $\mathrm{Cu}$ & 0.34 & 0.027 & -6.3 & -0.97 & 115.2 & 9.31 & 2.48 & 8.31 & 12.4 \\
\hline $\mathbf{P b}$ & 0.23 & 0.003 & -9.2 & -1.00 & 237.2 & 3.49 & 0.86 & 2.49 & 67.9 \\
\hline Zn & 3.01 & 0.043 & -5.7 & -0.96 & 533.4 & 7.54 & 2.01 & 6.54 & 70.7 \\
\hline $\mathrm{Ni}$ & 0.03 & 0.002 & 9.4 & -1.00 & 30.3 & 2.65 & -9.42 & 1.65 & 11.4 \\
\hline As & 0.10 & 0.065 & -4.5 & -0.93 & - & - & - & - & 1.5 \\
\hline $\mathrm{Cr}$ & 0.09 & 0.001 & -10.4 & -1.00 & 86.7 & 1.04 & -0.55 & 0.04 & 83.4 \\
\hline Co & 0.28 & 0.066 & -5.1 & -0.93 & 18.2 & 4.42 & 1.50 & 3.42 & 4.1 \\
\hline
\end{tabular}

*Mean = Average metal conc. in $\mathrm{mg} / \mathrm{kg}$ in sediment; $\mathrm{AF}=$ Anthropogenic factor;

$\mathrm{MCI}=$ Metal contamination Index; Igeo = Geo-accumulation Index;

$\mathrm{LBC}=$ Local background concentration .

Such variability is a clear indication of the fact that the sources of the metal contaminations are related to anthropogenic point-source inputs through discharge of household/municipal wastes within the urban stretches. As a part of further data evaluation, the estimated single metal contamination factors (CF) were studied which indicates that $\mathrm{As}, \mathrm{Cu}$ and $\mathrm{Cr}$ have low degree of contamination in all the analyzed water samples. Other trace metals $(\mathrm{Pb}$, $\mathrm{Zn}$, and $\mathrm{Ni}$ ) have $\mathrm{CF}>5$ which indicate moderate to very high contamination based on Hakanson classification scheme [24]. This is a consistent with the observed concentrations and hence a further indication of anthropogenic sources of $\mathrm{Pb}, \mathrm{Zn}$, and $\mathrm{Ni}$, through wastewater discharge into the stream networks within the urban catchments.

\subsection{Assessment of trace metal contamination in the sediment phase}

Table 3 presents the average distribution of adsorbed and total concentrations of the analysed trace/heavy metals in the sediment alongside other contamination indices for the study urban stream network. In the analyzed stream sediments, the adsorbed trace metals are considerably lower, with average concentrations of $0.1-3.01 \mathrm{mg} / \mathrm{kg}$ compared to the respective total metal concentrations of $18.2-533.4 \mathrm{mg} / \mathrm{kg}$. Such low proportion of adsorbed total metal concentration is an indication of low bioavailability of adsorbed metal concentrations despite potential geogenic input source.

The variability of the adsorbed $\mathrm{Cu}, \mathrm{Pb}$ and $\mathrm{Zn}$ in the stream sediments along the urban stretches of the stream networks (Figure 5) is a further confirmation of the anthropogenic point source inputs. The estimated AF revealed low enrichment for the adsorbed metals ( 0.002 to 0.09) within the sediment phase relative to the natural geogenic background concentrations in the underlying bedrocks. This is consistent with the negative values of the estimated Igeo $(-4.5$ to -10.4$)$, which in addition to 
negative values of MCI ( -1.0 to -0.93$)$, clearly suggest dominant local geogenic/pedogenic controls rather than anthropogenic contamination with respect to the adsorbed metal concentrations in the stream sediments.

However, the total metal concentrations in the sediments exhibited high estimated AF of 1.1 to 9.3, positive values of the estimated $\mathrm{I}_{\text {geo }}(0.9-2.0)$ and metal contamination index (MCI) of 2.5-8.3 (Table 3). These are indications of medium to high level enrichment (of 2 to 10 factor) with respect to the local natural geogenic/pedogenic concentration (LBC) within the catchment area (with the exception of $\mathrm{Cr}$ and $\mathrm{Ni}$ which exhibit very low enrichment level). Hence it can be concluded that though the adsorbed metal concentrations in the sediment samples suggests little/no contamination, the enrichment revealed by the respective total metal concentrations in the stream sediments is an indication of potential contamination threat due to possible re-mobilization into the water column.

Although the adsorbed metal concentrations in the sediment sample indicate no contamination with respect to the local natural geogenic concentrations in the underlying bedrocks, the estimated $\mathrm{K}_{\mathrm{d}}$ values of $>1$ indicate preferential partitioning of most of the metals in the sediment phase (Table 2). This is a further confirmation of potential contamination threat, through possible remobilization into the water phase in response to changes in physico-chemical conditions. In addition, the observed similar peaks/trends of the electrical conductivity (EC) and contamination indices of some trace metals as shown in Figure 6 is also a clear confirmation of anthropogenic point source discharge of waste water within the urban stretches. Similar trend had been reported in urban stream network of Ogunpa River in Ibadan metropolis [23]. Therefore, it can be concluded that despite low adsorbed geogenic metal concentrations in stream sediments, point-source anthropogenic inputs of wastewater into urban stream network can significantly enhance remobilization and bioavailability trace/heavy metals in the drainage environments.

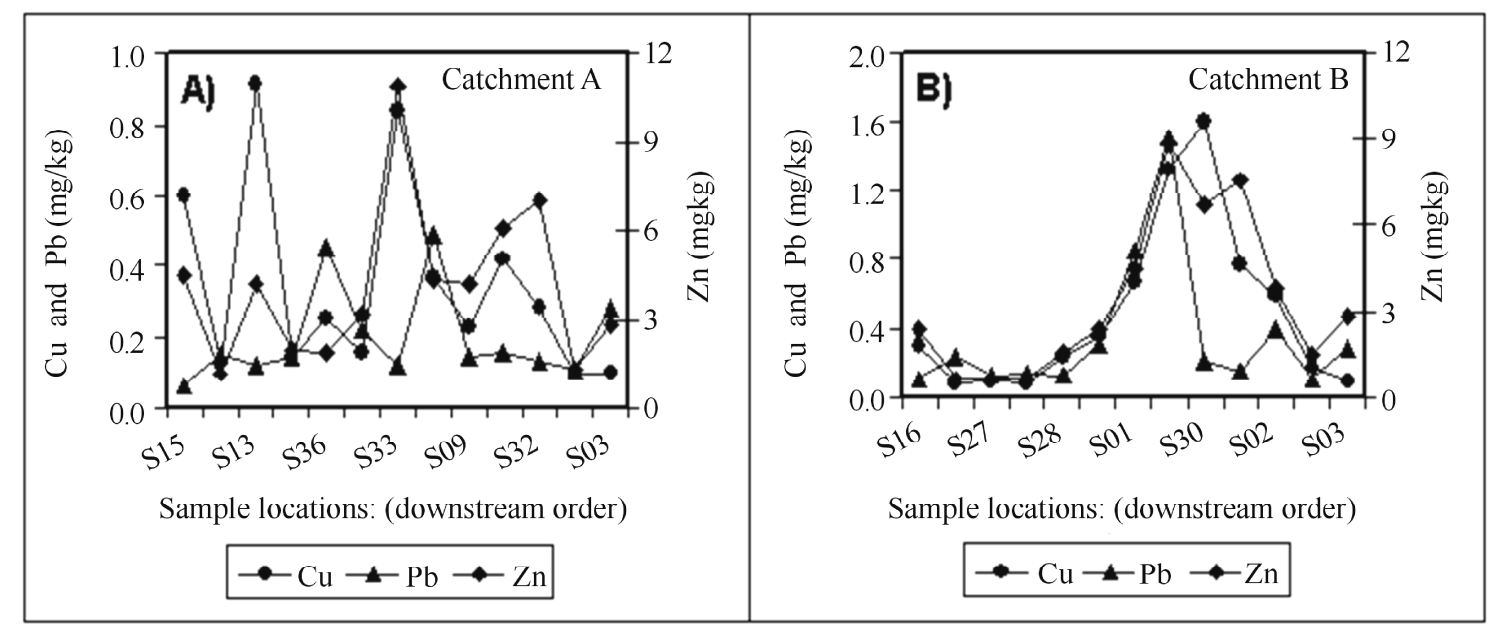

Figure 5. Profiles of trace metal concentrations in bottom sediments of the drainage catchment A and B within Osogbo township.

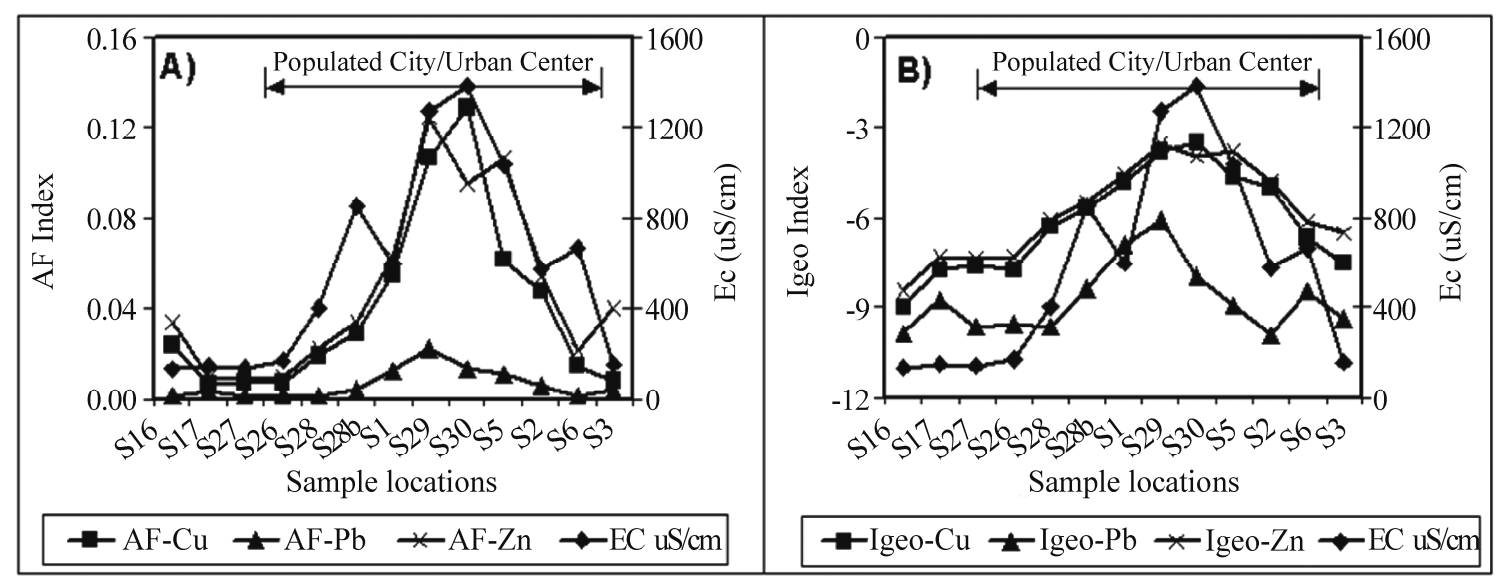

Figure 6. Profiles of EC ( $\mu \mathrm{S} / \mathrm{cm})$ against (A) Anthropogenic factor (B) Geo-accumulation Index along the drainage system. 


\section{Conclusions}

This study highlighted the influence of anthropogenic activities in terms of trace metals contamination of urban drainage systems characterized by lack of proper waste disposal/management practices. Assessment of urban drainage system in Osogbo-Township, SW-Nigeria, revealed impacts of untreated wastes discharge on dissolve trace metal concentrations on one hand. On the other hand the study also revealed enrichment of the metals, most especially the total metal concentrations in the stream sediments over the respective baseline concentration. The environmental implication of high enrichment of the trace metals with reference to the baseline (bedrock geology) lies in the potential release and contamination threat through weathering-pedological and erosiontransport processes. This is more so in such humid tropical setting like the present study where apparently high rate of weathering is associated with erosion/run-off of the tropical monsoon rains.

The adsorbed concentrations in the sediment samples indicate no contamination with respect to the background concentration in the underlying bedrocks. However, the dominance of adsorbed concentration of the respective metals over the dissolved contents as indicated by $\mathrm{Kd}>1$ for most of the trace metals is an indication of preferential partitioning in the sediment phase. This is consistent with the enrichment of the total metal concentrations over the baseline concentration, which constitutes potential danger for further contamination due to possible remobilization and re-dissolution into the water phase. Such remobilization could be favored by changes in the physico-chemical milieu ( $\mathrm{pH}, \mathrm{Eh}$, etc) resulting from the anthropogenic inputs of untreated domestic and municipal effluents from urban catchment.

\section{Acknowledgements}

The sponsorship of the JSPS, Japan for the first authors is gratefully acknowledged while the help of Merssers T. Mine and T. Shigeeda with ICP analyses and that of Mr. $\mathrm{K}$. Watanabe for the XRF analyses are also appreciated. In addition, the helpful comments and suggestions of the anonymous reviewer are also gratefully appreciated.

\section{References}

[1] A. G. Darnley, "International geochemical mapping: A new global project," In: A. G. Darnley, A. G. Garrett, (Eds.), International Geochemical Mapping. Jour. Geochem. Explor., Vol. 39, pp. 1-14. 1990.

[2] M. D. Cocker, "Geochemical mapping in Georgia, USA: A tool for environmental studies, geologic mapping and mineral exploration," Jour. Geochem. Explor., Vol. 67, pp. 345-360, 1999
[3] P. N. Ranasinghe, G. W. A. R. Fernando, C. B. Dissanayake, and M. S. Rupasinghe, "Stream sediment geochemistry of the Upper Mahaweli River Basin of Sri Lanka-Geological and environmental significance," Journal of Geochemical Exploration, Vol. 99, pp. 1-28, 2008.

[4] J. O. Nriagu, "Global inventory of natural and anthropogenic emissions of trace metals to the atmosphere," Nature, Vol. 279, pp. 409-411, 1979.

[5] J. O. Nriagu and J. M. Pacyna, "Quantitative assessment of worldwide contamination of air, water, and soils by trace metals," Nature, Vol. 33, pp. 134-139, 1988.

[6] H. E. Allen, "Standards for metals should not be based on total metal concentrations," SETAC-Europe News, Vol. 8, pp. 7-9, 1997.

[7] M. G. Vijver, J. Spijker, J. P. M. Vink, and L. Posthuma, "Determining metal origins and availability in fluvial deposits by analysis of geochemical baselines and solidsolution partitioning measurements and modeling," Environmental Pollution, Vol. 156, pp. 832-839, 2008.

[8] J. Viersa, B. Dupréa, and J. Gaillardet, "Chemical composition of suspended sediments in World Rivers: New insights from a new database," Science of the Total environment, Vol. 407, pp. 853-868, 2009.

[9] W. Salomon and U. Foerstner, "Metals in the hydrocycle," Springer-Verlag, Berlin Heidelberg, New York. 1984.

[10] M. A. Olade, "Heavy metal pollution and the need for monitoring: Illustrated for developing countries in west Africa," In: Hutchinson T, Meema K, editors. Lead, Mercury, Cadmium and Arsenic in the environment, SCOPE, John Wiley and Sons., pp. 335-341, 1987.

[11] J. L. Mogollon, C. Bifano, and B. E. Davies, "Geochemistry and anthropogenic inputs of metals in a tropical lake in Venezuela," Appl Geochem, Vol. 11, pp. 605-616, 1996.

[12] P. C. Paul and K. C. Pillai, "Trace metals in a tropical river environment-distribution," Water Air Soil Pollute. Vol. 19, pp. 63-73, 1983.

[13] R. J. Gibbs, "Transport phases of transition metals in the Amazon and Yukon Rivers," Geol. Soc. Am. Bull., Vol. 88, pp. 829-843, 1977.

[14] G. Mueller, "Schwermetalle in den Sedimenten des Rheins-Veraenderungen seit 1971," Umschau., Vol. 79, pp. 778-783, 1979.

[15] G. Mueller, "Die Schwermetallbelastung der Sedimenten des neckars und Seiner Nebenfluesse," Chemiker-Zeitung, Vol. 6, pp. 157-164, 1981.

[16] M. A. Rahaman, "Review of the basement geology of southwestern Nigeria," In C. A. Kogbe, (Ed) Geology of Nigeria. Elizabethan Publishers, Lagos, Nigeria. pp. 41-58, 1976.

[17] M. O. Oyawoye, "The basement complex of Nigeria," In: T. F. J. Dessauragie, and Whiteman (Eds), African Geology. Ibadan University Press, Nigeria, pp. 67-78, 1970. 
[18] I. B. Odeyemi,."A review of orogenic events in the Precambrian Basement of Nigeria, West Africa," Geologische Rundschau, Vol. 70, No. 3, pp. 897-909, 1981.

[19] J. D. Stednick, "Wildland water quality sampling and analysis," Academic Press Inc., San Deigo, 216p, 1991.

[20] R. A. Sutherland, "Bed sediment-associated trace metals in an urban stream, Oahu, Hawaii," Environ Geol., Vol. 39, pp. 611-627, 2000..

[21] K. Loska, D. Wiechula, and I. Korus, "Metal contamination of farming soils affected by industry," Environment International, Vol. 30, pp. 159-165, 2004.

[22] M. Meybeck, A. J. Horowitz, and C. Grosbois, "The geochemistry of Seine River Basin particulate matter: Distribution of an integrated metal pollution index," Sci. Tot. Environ., Vol. 328, pp. 219-236, 2004.

[23] M. N. Tijani, K, Jinno, and Y. Hiroshiro, "Environmental ompacts of heavy metal distribution in water and stream sediments of Ogunpa river Ibadan, SW Nigeria," Jour. Mining and Geol., Vol. 40, No. 1, pp. 73-83, 2004.

[24] L. Hakanson, "An ecological risk index for aquatic pollution control-A sedimentological approach," Water Res. Vol. 14, pp. 975-1001, 1980.
[25] J. H. Trefry, S. Metz, and R. P. Trocine, "A decline in lead transport by Mississippi River," Science, Vol. 230, pp. 439-441, 1985.

[26] S. J. Schropp, F. G. Lewis, H. L. Windom, J. D. Ryan, F. D. Calder, and L. C. Burney, "Interpretation of metal concentrations in estuary sediments of Florida using aluminum as a reference element," Estuaries, Vol. 13, pp. 227-235, 1990.

[27] K. C. Sahu and U. Bhosale, "Heavy metal pollution around the island city of Bombay, India-Part I: Quantification of heavy metal pollution of aquatic sediments and recognition of environmental discriminants," Chemistry Geology, Vol. 91, pp. 263-283, 1991.

[28] M. Singh, A. A. Ansari, G. Mueller, and I. B. Singh, "Heavy metals in freshly deposited sediments of the Gomati River (a tributary of the Ganga River): Effects of human activities," Environ Geol., Vol. 29, pp. 247-252, 1997.

[29] B. R. Manjunatha, K. Balakrishna, R. Shankar, and T.R. Mahalingam, "Geochemistry and assessment of metal pollution in soils and river components of a monsoon dominated environment near Karwar, southwest coast of India,” Environ Geol., Vol. 40, pp. 1462-1470, 2001. 